\title{
Epithelial changes with corneal punctate epitheliopathy in type 2 diabetes mellitus and their correlation with time to healing
}

Jing-hao Qu', Li Li', Lei Tian', Xiao-yu Zhang1', Ravi Thomas ${ }^{1,3,4}$ and Xu-guang Sun ${ }^{1 *}$

\begin{abstract}
Background: To study basal epithelial cell (BEC), sub-basal nerve plexus (SBN) and Langerhans cell (LC) density in patients with type 2 diabetes mellitus (T2DM) with corneal punctate epitheliopathy (CPE) and to assess their association with time to healing of CPE.

Methods: Retrospective study of in vivo confocal microscopy (IVCM) in 160 eyes from 160 patients with T2DM diagnosed with CPE due to a single cause. Key exclusion criteria included multiple-causes for CPE or treatment with autologous serum. A total of 149 eyes from 149 gender- age- and aetiolgy-matched patients with CPE without T2DM comprised the control group. Electronic records were reviewed for demographic features, history of T2DM and aetiology of CPE. Density of BEC, SBN and LC were compared between the two groups.

Results: The healing time in days for CPE with different aetiologies in the T2DM and control groups were as follows: dry eye $(21.56 \pm 2.41 ; 7.00 \pm 2.19 ; P=0.001)$; meibomian gland dysfunction $(26.42 \pm 6.04 ; 9.21 \pm 2.55 ; P=0.001)$; cataract extraction $(38.00 \pm 19.62 ; 25.83 \pm 11.49 ; P=0.043)$; drug induced $(53.19 \pm 18.83 ; 41.86 \pm 23.87 ; P=0.018)$ and exposure $(38.25 \pm 14.13 ; 29.00 \pm 13.67 ; P=0.026)$. LC density was $38.70 \pm 9.65$ cells $/ \mathrm{mm}^{2}$ in the T2DM group comparedwith $25.53 \pm 3.54$ cells $/ \mathrm{mm}^{2}$ in the controls $(P=0.001)$. SBN density was $11.76 \pm 1.69 \mathrm{~mm} / \mathrm{mm}^{2}$ in the T2DM group compared with $20.92 \pm 1.43 \mathrm{~mm} / \mathrm{mm}^{2}$ in the controls $(P=0.001)$. BEC density in the T2DM group was $4982 \pm 1178$ cells $/ \mathrm{mm}^{2}$ compared with $5739 \pm 394$ cells $/ \mathrm{mm}^{2}$ in the control group $(P=0.018)$. Age and duration of T2DM had no relationship with healing time (multiple linear regression, $P=0.618 ; P=0.787$ ). The density of $L C$ in the T2DM group showed a negative correlation with SBN density $\left(r=0.350 ; R^{2}=0.1225 ; P=0.034\right)$. The density of SBN in the T2DM group showed a positive correlation with BEC density $\left(r=0.427 ; R^{2}=0.1823 ; P=0.008\right)$. The density of BEC in the T2DM group showed a negative correlation with healing time $\left(r=0.931 ; R^{2}=0.8668 ; P=0.001\right)$.
\end{abstract}

Conclusions: Utilising IVCM, we have demonstrated increased LC and decreased SBN in patients with T2DM and CPE. Both may be related to lower BEC density and nuclei enhanced reflection. Furthermore, decreased BEC density may lead to delay in cornea epithelium healing in the T2DM group comparedwith controls. An immune-mediated response may play a role in delayed wound closure in patients with T2DM.

Keywords: Type 2 diabetes mellitus, Corneal punctate epitheliopathy, Langerhans cell, Subbasal nerve plexus, Basal epithelial cell

\footnotetext{
* Correspondence: sunxg1955@163.com

${ }^{1}$ Beijing Institute of Ophthalmology, Beijing Tongren Eye Center, Beijing

Tongren Hospital, Capital Medical University; Beijing Ophthalmology \& Visual

Sciences Key Laboratory, Beijing 100730, China

Full list of author information is available at the end of the article
} 


\section{Background}

An estimated 415 million people were reported to have diabetes mellitus in 2017 and this figure is projected to rise to 642 million by 2040, an increase of 55\% [1]. Type 2 diabetes mellitus (T2DM) is closely related to modern lifestyle, ageing and obesity and is associated with numerous systemic and ocular complications. While diabetic retinopathy (DR) is the commonest ocular complication and a leading cause of blindness worldwide, the ocular surface can also be affected. T2DM affects the morphological, physiological, metabolic and clinical state of the cornea, and microstructural changes can still exist even with a normal slit lamp examination and can predispose patients to disease [2]. The prevalence of corneal abnormalities such as punctate keratitis, recurrent corneal erosion syndrome, persistent epithelial defects, reduced corneal sensitivity and endothelial damage is increased in diabetics $[3,4]$.

The corneal epithelium is an important defensive barrier of the ocular surface [5]. Patients with T2DM have epithelial basement membrane abnormalities in the nervous system, skin, kidney, retina and cornea [6-9]. The effects of T2DM impact epithelial basal cells, the epithelial basement membrane as well as sub-basal nerve plexus (SBN) and can lead to epitheliopathy and corneal adhesion disorders [10]. Basement membrane changes in T2DM can affect the corneal epithelium and predispose to infections. Such changes include a reduction in corneal epithelial basal cells (BEC) as well as an increase in thickness and irregularity of the corneal epithelial basement membrane $[7,11]$. T2DM affects the corneal SBN leading to a reduction in SBN density [12]. Furthermore, it is of interest that Cornea confocal microscopy (CCM) has revealed an increase in the number of highly reflective cells, 'presumably dendritic cells', in the cornea of patients with diabetes [13]. These cells were subsequently identified as Langerhans cell (LC) [14].

In vivo confocal microscopy (IVCM) has become the standard tool for assessing the living cornea at a cellular level both in diseases states and in healthy subjects [15]. The instrument has excellent repeatability and reproducibility in the evaluation of the corneal epithelium, sub-basal nerve plexus (SBN) and LC density, in both healthy controls and in people with T2DM [16-18].

Corneal punctuate epitheliopathy (CPE) refers to a group of diseases that show dot-like staining of the corneal epithelium. Patients complain of sharp pain, tearing, redness, foreign body sensation, photophobia and decreased vision. The manifestations of CPE include an increase in corneal epithelial permeability, epithelial edema and dot-like staining. If untreated or incorrectly treated,CPE can lead on to corneal ulceration [10].
The objective of this study was to examineBEC, SBN and LC density in CPE in patients with T2DM and report their association with time to healing of CPE.

\section{Methods}

A total of 928 patients received a diagnosis of $\mathrm{CPE}$ during the study period fromNovember 2010 to October 2015. Patientsfor whom CPE was attributed to multiple factors (a single causes could not be established, single cause include: dry eye; MGD; cataract extraction; drug; exposure) and who had undergone previous corneal or ocular surgery, had any ocular pathology other than diabetic retinopathy and keratopathy were excluded. One eye of each patient was selected for analysis, and in patients with bilateral CPE, the most severely affected eye was selected. The Ethics Committee of the Tongren Hospital (Beijing, China) approved the study.

In all, 160 eyesfrom 160 patients with T2DMand CPE were eligible for inclusion in the study. The control group consisted of 149 eyesfrom 149 gender-, age- and aetiology-matched patients with CPE without T2DM who were seen during the study period.

All patients underwent visual acuity testing as well as slit lamp biomicroscopic examination with fluorescein staining. A corneal specialist made the diagnosis of CPE based on a combination of symptoms and clinical signs and determined theaetiology. The symptoms included a combination of sharp pain, tearing, redness, foreign body sensation, photophobia and decreased vision combined with more than 5 spots of epithelial dots that stained with fluorescein [10]. Other data collected included age, sex, affected eye, worse affected eye, history of surgery, use of ocular medication, presence of MGD and T2DM. T2DM was diagnosed based on the standards of medical care in diabetes [19].

CPE was divided into the following aetiological categories:

1. Dry eye related: normal eye lid margin with tear film break up time (TFBUT) $<5 \mathrm{~s}$, Schirmer1test $<5 \mathrm{~mm} / 5 \mathrm{~min}$ [20];

2. Meibomian gland disease (MGD) related: patients with lid signs of MGD [21];

3. Cataract extraction related: CPE occurring within 2 weeks of surgery in the absence of medication use (as detailed below), dry eye or MGD.

4. Drug related: CPE in those using eye drops (tobramycin or dexamethasone) or ganciclovir gel for more than 1 month and absence of dry eye and MGD;

5. Exposure related: CPE resulting from corneal exposure with corneal staining located inferiorly in the area of exposure, in the absence of dry eye and MGD. 

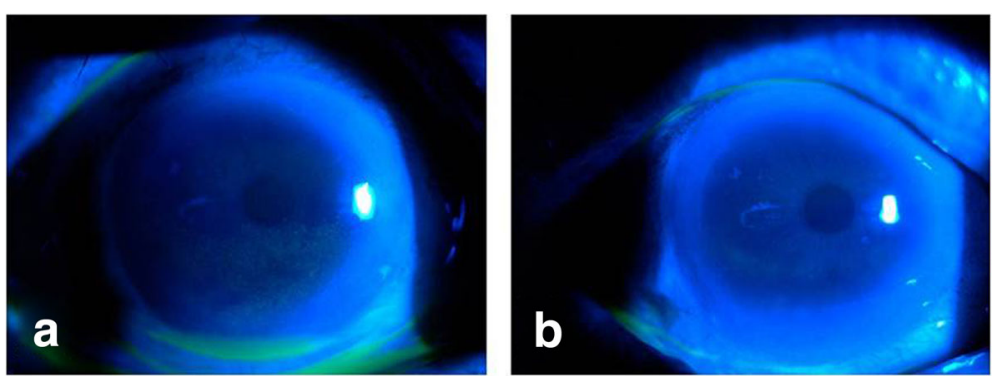

Fig. 1 Pre and post treatment photograph of a patient with T2DM and CPE. a Pre-therapy corneal punctate epitheliopathy (corneal epithelial dot staining positive). $\mathbf{b}$ Post-therapy showing absence of fluorescein staining

All patients underwent IVCM in both eyes using the Heidelberg Retina Tomograph III Rostock Cornea Module (HRT III RCM; Heidelberg Engineering GmbH, Heidelberg, Germany). Genteal Gel (0.2\% carbomer eye drops; Dr. Gerhard Mann, Chem.-Pharm, Fabrik GmbH) was applied in a disposable sterile polymethylmethacrylate cap (Tomo-Cap; Heidelberg Engineering GmbH)placed on the tip of the objective lens. A drop of local anaesthetic ( $0.4 \%$ tetracaine hydrochloride) was administered to both eyes and the subject was asked to fixate on a distant target before commencing scanning of the central cornea. A single experienced and masked examiner performed all scans. Section scans of the central cornea were recorded with the Heidelberg HRT-III microscope, using $384 \times 384$ pixels and a field of view of $400 \times 400 \mu^{2}$.

One randomly selected eye from each person in the control group was used for analysis. Three good quality images of the LC, SBN and BEC were selected and were

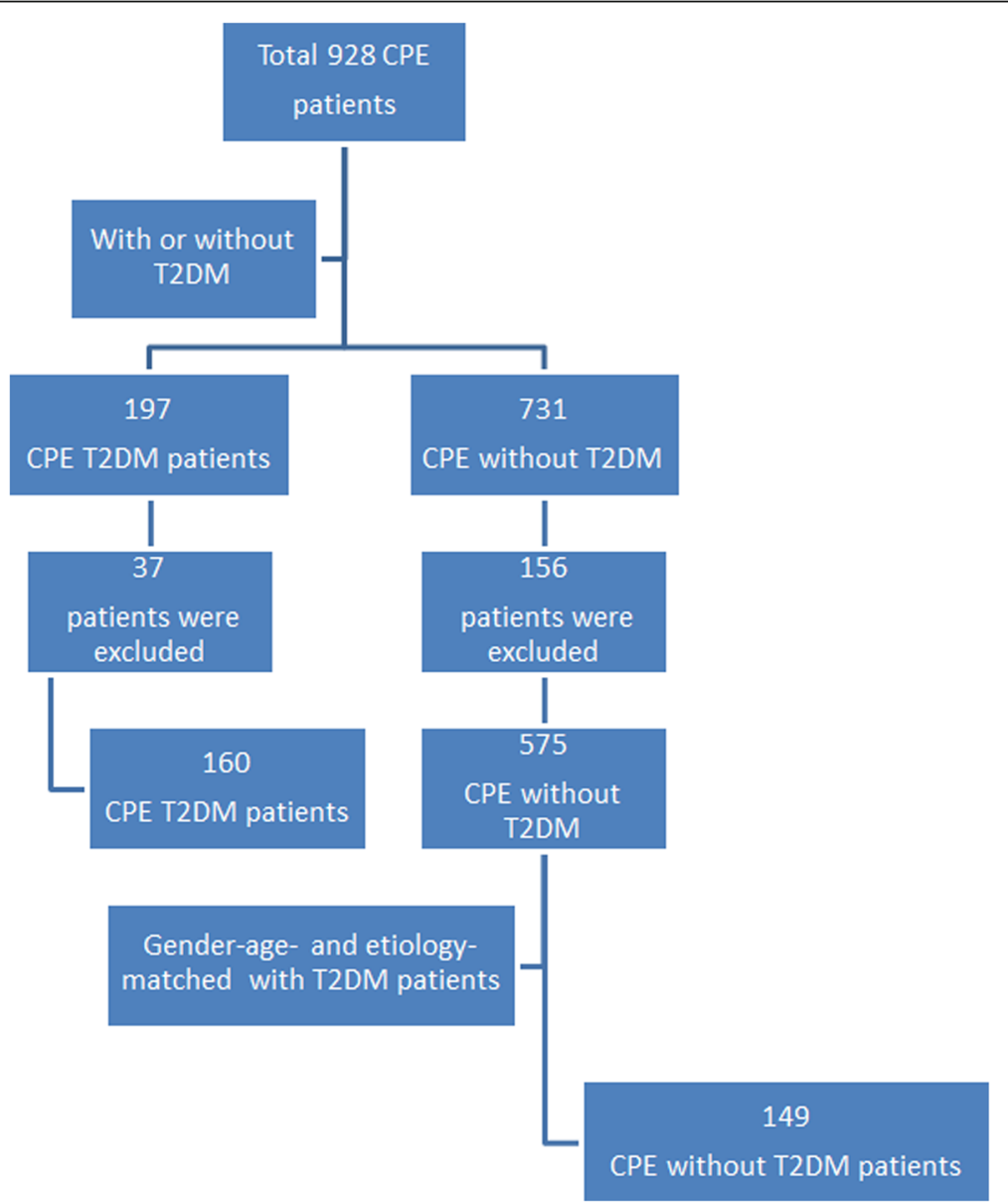

Fig. 2 Number of patients included in the study (gender: $X 2$ analysis, $P>0.05$; age: two samples rank sum test, $P>0.05$ ) 
Table 1 Healing time of CPE in T2DM patients and controls

\begin{tabular}{llll}
\hline & Eyes & $\begin{array}{l}\text { Days to healing } \\
\text { (mean } \pm \text { SD) }\end{array}$ & $P$ values \\
\hline Dry eye & & $21.56 \pm 2.41$ & $P=0.001$ \\
T2DM & 40 & $7.00 \pm 2.19$ & \\
Controls & 35 & $26.42 \pm 6.04$ & $P=0.001$ \\
MGD & & $9.21 \pm 2.55$ & \\
T2DM & 42 & & \\
Controls & 37 & $38.00 \pm 19.62$ & \\
Cataract extraction & & $25.83 \pm 11.49$ & \\
T2DM & 38 & & $P=0.018$ \\
Controls & 35 & $53.19 \pm 18.83$ & \\
Drug & & $41.86 \pm 23.87$ & \\
T2DM & 20 & & \\
Controls & 21 & $38.25 \pm 14.13$ & \\
Exposure & & $29.00 \pm 13.67$ & \\
T2DM & 20 & $25.97 \pm 18.21$ & \\
Controls & 21 & & \\
Total & 309 & & \\
\hline
\end{tabular}

used for image analysis by the examiner. The average of three measurements was used for further comparative analysis [22]. The basal epithelium was defined as the first three clear scans anterior to Bowman's layer. BEC was measured manually using HRT III proprietary software.On average, three quality images of Bowman's layer were used to quantify both Langerhans cell density and nerve fibre morphology in all patients and controls, and the average results of all these images were calculated. SBN density was defined as the total nerves lengths in units of $\mathrm{mm} / \mathrm{mm}^{2}$ [23]. SBN was analysed in three selected high-quality images using NeuronJ software
(Erik Meijering). NeuronJ is an ImageJ (National Institutes of Health, Bethesda, MD) plugin to facilitate the tracing and quantification of elongated image structures [24].

The therapy for CPE was standardized and included sodium hyaluronate eye drops and de-proteinized calf blood extract eye gel 4 times a day [25]. All patients were examined within 3-7 days of the initiation of treatment and at a similar interval thereafter untill healing was complete.

The healing time was defined as the number of days from the onset of treatment to the day the corneal epithelial fluorescein staining became negative. An example of a patient with T2DM who developed CPE following cataract surgery is shown in Fig. 1. Corneal staining resolved 21 days after the initiation of treatment.

All statistical analyses were performed with SPSS (version 18.0). Chi-square analysis, two samples rank sum test, Pearson correlation and multiple linear regression were used. $P<0.05$ was considered to be statistically significant.

\section{Results}

Of the 928 patients diagnosed with CPE during the study period, 197 had T2DM. Thirty-seven patients with T2DM and 156 controls for whom a single aetiological category could not be identified as the cause for CPE were excluded. Included were160 patients (62 males; 98 females) and 149 controls (60 males; 89 females) with an average age of $59.8 \pm 11.6$ and $58.9 \pm 14.9$ years respectively (Fig. 2). The duration of T2DM was $13.4 \pm$ 8.30 year (from 1 to 30 years).

The cause of CPE in the T2DM group were dry eye (40, 25.0\%), meibomian gland dysfunction (40, 25.0\%), cataract extraction $(38,23.8 \%)$, drug induced $(21,13.1 \%)$ and exposure $(21,13.1 \%)$. The control group was matched for gender, age andaetiology. The cause of CPE in the

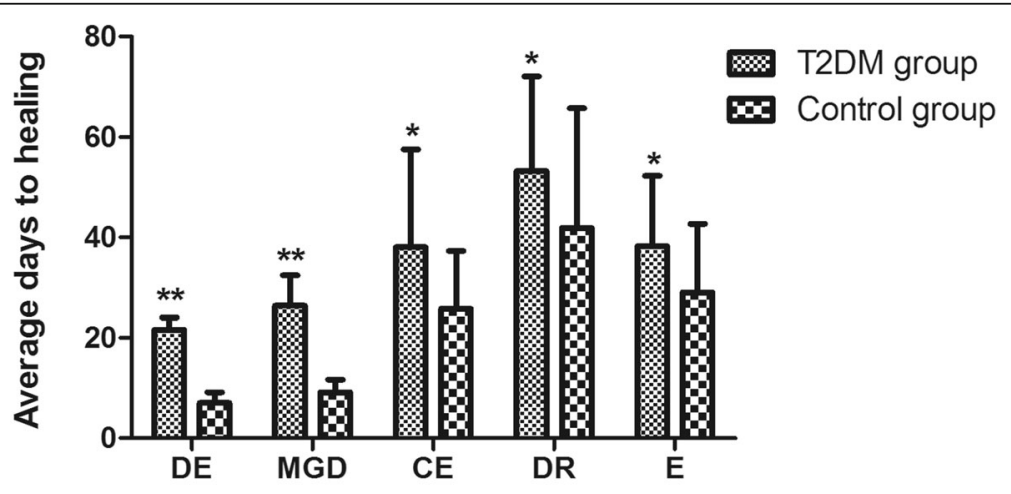

DE: Dry eye; CE: Cataract extraction ; DR: Drug related; E: Exposure.

$* \boldsymbol{P}<\mathbf{0 . 0 5 * * \boldsymbol { P } < 0 . 0 1}$

Fig. 3 Healing timesfor CPE in patients with T2DM and controls. Healing times were significantly higher in theT2DM group irrespective of aetiology 
Table 2 LC density (cells $/ \mathrm{mm}^{2}$ ), basal epithelial cell density (cells $/ \mathrm{mm}^{2}$ ) and SBN density $\left(\mathrm{mm} / \mathrm{mm}^{2}\right.$ ) in T2DM and control group

\begin{tabular}{lllll}
\hline & Age $($ mean \pm SD) & LC density & SBN density & BCE density \\
\hline Type 2 DM & $59.8 \pm 11.6$ & $38.70 \pm 9.65$ & $11.76 \pm 1.69$ & $4982 \pm 1178$ \\
Control & $58.9 \pm 14.9$ & $25.53 \pm 3.54$ & $20.92 \pm 1.43$ & $5739 \pm 394$ \\
\hline
\end{tabular}

LC density using two samples rank sum test $P=0.001$; SBN density using two samples rank sum test $P=0.001$; BCE density using two samples rank sum test $P=0.018$

control group were dry eye (38, 25.5\%), meibomian gland dysfunction (38, 25.5\%), cataract extraction (34, 22.8\%), drug induced $(19,12.8 \%)$ and exposure $(20,13.4 \%)$.

The healing times for the different categories of CPE in the T2DM and control groups are shown in Table 1 and Fig. 3. The healing times were longer in T2DM patients across all aetiologic categories.

Results of the ICVM examination were shown in Table 2. The proportion of individuals with LC was significantly higher in the T2DM group $(82.1 \%)$ compared with the control group $(46.1 \%, P=0.001)$. LC density was also significantly higher in diabetic patients compared with controls $\left(38.70 \pm 9.65 \mathrm{cells} / \mathrm{mm}^{2}\right.$ vs $25.53 \pm 3.54$ cells $/ \mathrm{mm}^{2}, P=0.001$; Fig. 4 a). Central corneal SBN density was $11.76 \pm 1.69 \mathrm{~mm} / \mathrm{mm}^{2}$ in T2DM vs
$20.92 \pm 1.43 \mathrm{~mm} / \mathrm{mm}^{2}$ in controls $(P=0.001 ;$ Fig. $4 \mathrm{~b})$. BEC density in the T2DM group $\left(4982 \pm 1178\right.$ cells $\left./ \mathrm{mm}^{2}\right)$ was significantly lower than that in the control group (5739 \pm 394 cells $\left./ \mathrm{mm}^{2} ; P=0.018\right)$ (Fig. 4c).

Age and duration of T2DM had no relationship with healing time (multiple linear regression, $P=0.618 ; P=$ 0.787). The density of LC in the T2DM group showed a negative correlation with SBN density (Fig. 5a; Pearson correlation $r=0.350 ; \mathrm{R} 2=0.1225 ; P=0.034$ ). There was no correlationbetween LC density and SBN density in the control group $(r=0.027 ; P=0.913)$. The density of SBN in the T2DM group showed a positive correlation with BEC density (Fig. 5b; Pearson correlation $r=0.427$; $\mathrm{R} 2=0.1823 ; P=0.008)$. There was no correlation between SBN density and BEC density in the control group $(r=-0.104 ; P=0.673)$. The density of BEC in the T2DM group showed a negative correlation with healing time (Fig. 5c; Pearson correlation $r=0.931 ; \mathrm{R} 2=0.8668 ; P=$ $0.001)$. There was no correlation between BEC density with healing time in the control group $(r=-0.150 ; P=0.540)$.

\section{Discussion}

Age and duration of T2DM had no relationship with healing time. The key finding is that SBN density was decreased in patients with CPE and T2DM, while BEC
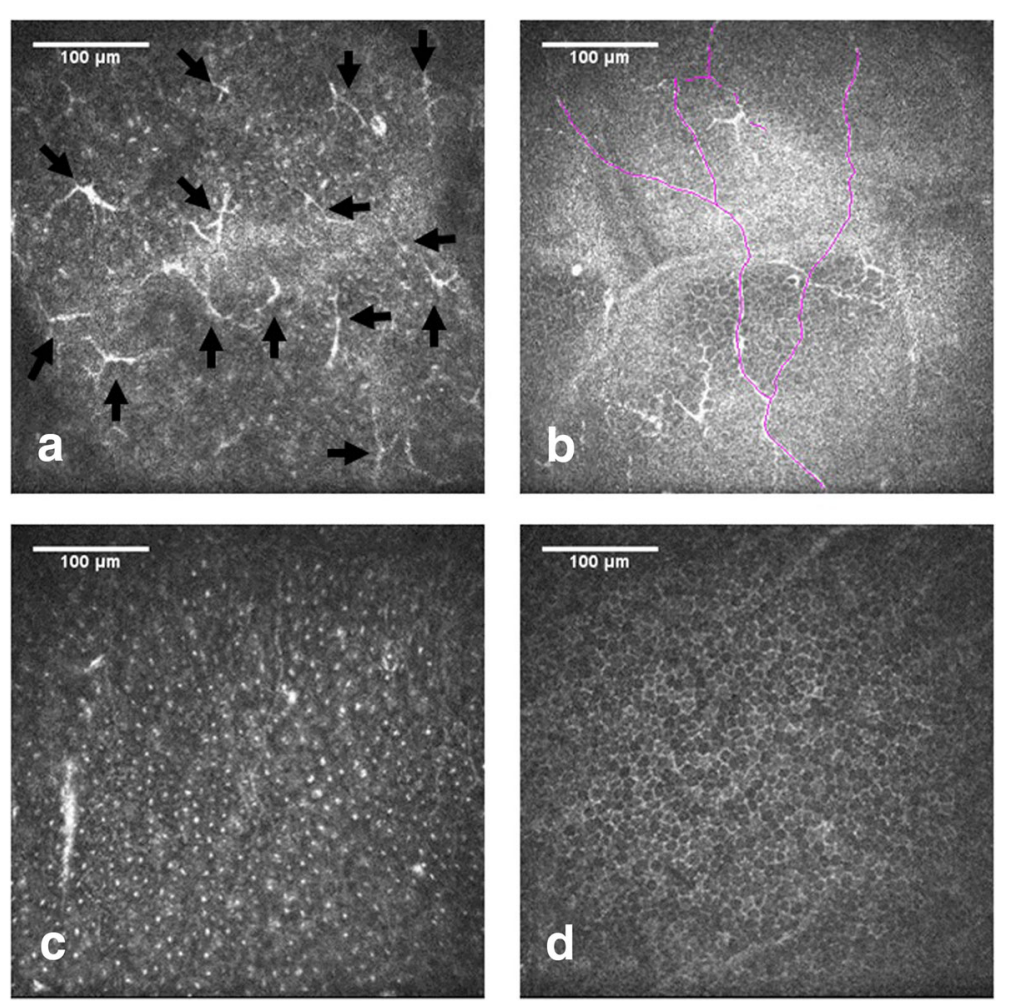

Fig. 4 ICVM of basal epithelial cells in a patient with T2DM (a-c) and a control patient (d). Images from Bowman's layer of the cornea with highly reflective Langerhans cell shown by black arrows (a); representative image showing decreased SBN density in T2DM (b); patient with T2DM showing lower basal epithelial cell density (c) 

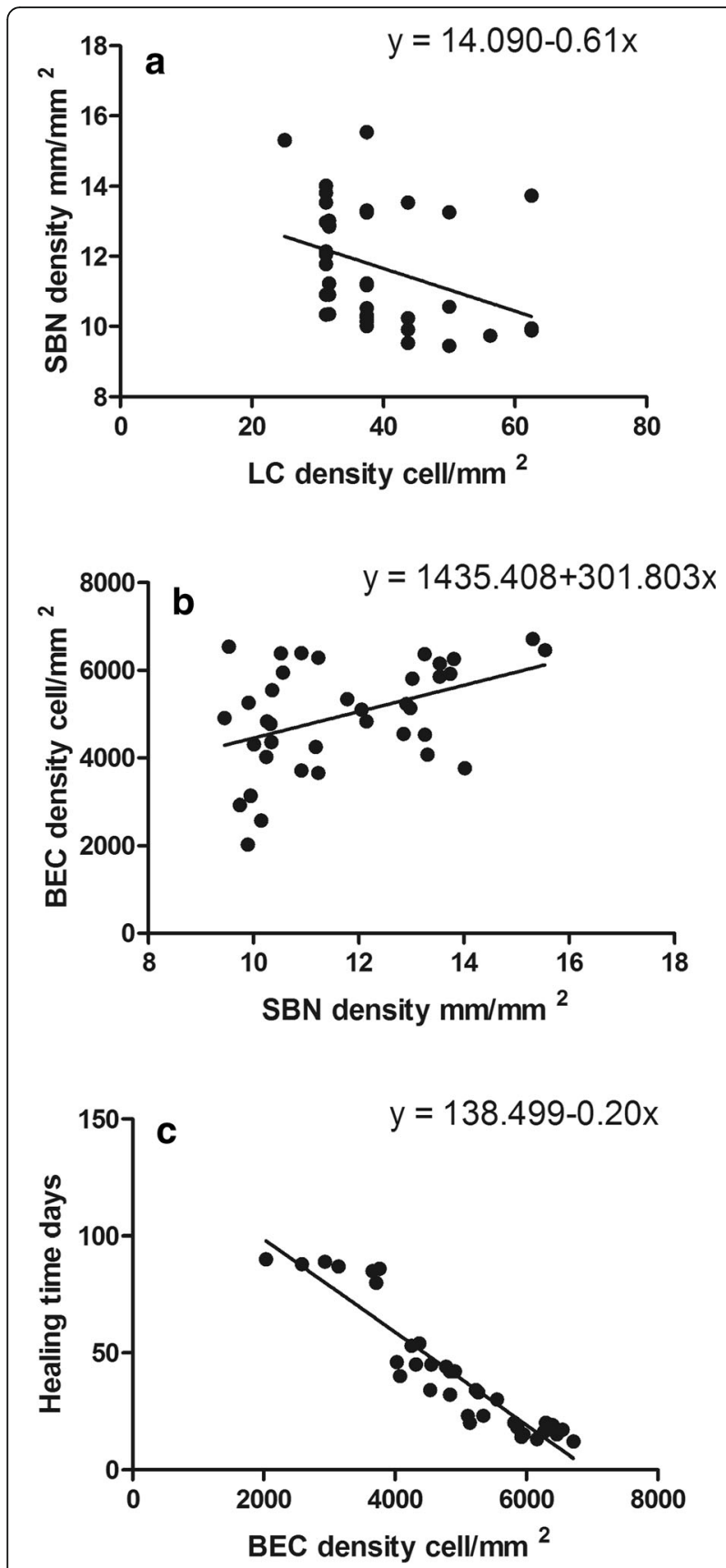

Fig. 5 Correlation with healing time, LC, SBN and BEC. The density of LC in the T2DM group showed a negative correlation with SBN density (a); the density of SBN in the T2DM group showed a positive correlation with BEC density (b); the density of BEC in the T2DM group showed a negative correlation with healing time (c)

density was also decreased and prolonged healing time. T2DM is one of the common causes of corneal nerve deficits and poor epithelium healing time [26]. The density of BEC in patients with CPE and T2DM was significantly lower than in the control group $(P=0.018$; Table 2).This results is similar to that of Quadrado et al. [11] and Chang et al. [27] who reported lower BEC density in patients with T2DM. The density of BEC in our study was lower than previous reports that compared patients with T2DM with healthy controls, because our study mainly focused on patients with CPE. The metabolism of corneal epithelial (cell proliferation, differentiation, migration, and death) depends on corneal innervation, T2DM patients' cornea decreased in SBN can result in the loss of BEC [10]. Corneal sensory nerves supply trophic neuropeptides, such as calcitonin gene-related peptide (CGRP). These compounds increase corneal epithelial cells' proliferation and modulate epithelial cell differentiation and migration [11]. The dysfunction of BEC could lead to prolonged in healing time.

The total nerve length that used in our study was a reliable measure of corneal nerve density [28]. Ziegler et al. [29] and Zhivov et al. [30] reported the SBN density in patients with T2DM, to be $19.7 \pm 7.5 \mathrm{~mm} / \mathrm{mm}^{2}$ and $6.2 \pm 4.4 \mathrm{~mm} / \mathrm{mm}^{2}$, respectively. We also showed that SBN density was decreased in patients with CPE and T2DM. The SBN density in patients with CPE without T2DM was quite similar with the earlier study we mentioned above.

LC was mainly located in the central and peripheral of cornea [31, 32]. Previous studies have [33] reported LC was located beneath the basal epithelial cells. The density of LC in our T2DM group $\left(38.70 \pm 9.65\right.$ cells $\left./ \mathrm{mm}^{2}\right)$ and control group $\left(25.53 \pm 3.54\right.$ cells $\left./ \mathrm{mm}^{2}\right)$ differs from the results reported by Tavakoli et al. $\left(17.73 \pm 1.45\right.$ cells $/ \mathrm{mm}^{2}$ verus $6.94 \pm 1.45$ cells $/ \mathrm{mm}^{2}$ ). However, the results reported by Mastropasquaare the same as those of our control group $\left(24 \pm 10 \mathrm{cell} / \mathrm{mm}^{2}\right)$ [34]. This is because HRT III has a higher resolution ratio for identifying LC when compared with the Tomey Confoscan corneal confocal microscope.

The density of BEC showed no relationship with healing time in the control group because the SBN density was normal in this group. In addition, the density of LC was increased in patients with CPE and T2DM. Tavakoli et al. [14] reported corneal nerve damage led to increased LC in T2DM patients. Immune mediated might contribution to corneal nerve damage in T2DM patients. In our study, the density of $\mathrm{LC}$ in the T2DM group showed a negative correlation with SBN density, providing support to Tavakoli's hypothesis. This suggests that SBN along with LC may play a role in delayed wound closure in T2DM patients.

These data provide support for the role of IVCM in the microstructural evaluation of the corneal epithelium and the associated factors with CPE. However, there are several limitations to our study. IVCM images were only from the first patient visit, and there are no post-treatment images for comparison. In addition, the glycaemic control data was not collected in T2DM patients. 


\section{Conclusions}

In summary, these data provide support for a potential immune-mediated role in delayed wound healing seen in patients with T2DMand CPE. In the future, mechanistic studies are warranted to define the basis of this immune-mediated damage with the goal of developing therapeutic strategies to shorten the healing time.

\section{Abbreviations}

BEC: Basal epithelial cell; CCM: Cornea confocal microscopy; CGRP: Calcitonin gene-related peptide; CPE: Corneal punctate epitheliopathy; DCs: Dendritic cells; IVCM: In vivo confocal microscopy; LC: Langerhans cell; MGD: Meibomian gland disease; SBN: Sub-basal nerve plexus; T2DM: Type 2 diabetes mellitus; TFBUT: Tear film break up time

\section{Acknowledgements}

Not applicable

\section{Funding}

No funding was received by any of the authors for the writing of this manuscript.

\section{Availability of data and materials}

The datasets during and/or analyzed during the current study are available from the corresponding author on reasonable request.

\section{Authors' contributions}

JHQ drafted the manuscript and performed the literature review. LL participated in information gathering and editing. $L T, X Y Z, R T$ and $X G S$ conceived the idea, managed the patients' ophthalmic conditions and supervised writing of this case report. All authors read and approved the final manuscript.

\section{Ethics approval and consent to participate}

This study was performed in accordance with the Declaration of Helsinki and was approved by the Ethics Committee of the Tongren Hospital, Beijing, China, and the approval number is TRCKY-023. Informed consent was obtained from all subjects after the aims and nature of the study were explained to the participants. Parental or legal guardian consent was obtained for all participants under the age of 16.

\section{Consent for publication}

Not applicable

\section{Competing interests}

The authors declare that they have no competing interests.

\section{Publisher's Note}

Springer Nature remains neutral with regard to jurisdictional claims in published maps and institutional affiliations.

\section{Author details}

${ }^{1}$ Beijing Institute of Ophthalmology, Beijing Tongren Eye Center, Beijing Tongren Hospital, Capital Medical University; Beijing Ophthalmology \& Visual Sciences Key Laboratory, Beijing 100730, China. ${ }^{2}$ The First Affiliated Hospital of Xi'an Jiaotong University, Xi'an 710061, China. ${ }^{3}$ Queensland Eye Institute, Brisbane, Australia. ${ }^{4}$ University of Queensland, Brisbane, Australia.

Received: 14 October 2016 Accepted: 4 December 2017

Published online: 04 January 2018

\section{References}

1. IDF diabetes atlas - Home. In., vol. 2017; 2017. http://www.diabetesatlas.org/

2. Rehany $U$, Ishii $Y$, Lahav M, Rumelt S. Ultrastructural changes in corneas of diabetic patients: an electron-microscopy study. Cornea. 2000;19(4):534-8.

3. Diez-Feijoo E, Grau AE, Abusleme El, Duran JA. Clinical presentation and causes of recurrent corneal erosion syndrome: review of 100 patients. Cornea. 2014;33(6):571-5

4. Schultz RO, Peters MA, Sobocinski K, Nassif K, Schultz KJ. Diabetic keratopathy as a manifestation of peripheral neuropathy. Am J Ophthalmol. 1983;96(3):368-71.
5. Leong $Y Y$, Tong L. Barrier function in the ocular surface: from conventional paradigms to new opportunities. OCUL SURF. 2015;13(2):103-9.

6. Bradley JL, Thomas PK, King RH, Watkins PJ. A comparison of perineurial and vascular basal laminal changes in diabetic neuropathy. Acta Neuropathol. 1994;88(5):426-32.

7. Taylor HR, Kimsey RA. Corneal epithelial basement membrane changes in diabetes. Invest Ophthalmol Vis Sci. 1981;20(4):548-53.

8. Vracko R. Basal lamina layering in diabetes mellitus. Evidence for accelerated rate of cell death and cell regeneration. Diabetes. 1974;23(2):94-104.

9. Ljubimov AV, Burgeson RE, Butkowski RJ, Couchman JR, Zardi L, Ninomiya Y, Sado Y, Huang ZS, Nesburn AB, Kenney MC. Basement membrane abnormalities in human eyes with diabetic retinopathy. J Histochem Cytochem. 1996:44(12):1469-79.

10. Holland EJ, Mannis MJ, Lee WB. Ocular surface disease : cornea, conjunctiva and tear film. London: Elsevier/Saunders; 2013.

11. Quadrado MJ, Popper M, Morgado AM, Murta JN, Van Best JA. Diabetes and corneal cell densities in humans by in vivo confocal microscopy. Cornea. 2006;25(7):761-8.

12. Mocan MC, Durukan I, Irkec M, Orhan M. Morphologic alterations of both the stromal and subbasal nerves in the corneas of patients with diabetes. Cornea. 2006:25(7):769-73.

13. Popper M, Morgado AM, Quadrado MJ, Murta JN, Best JV, Muller LJ. Subbasal nerves and highly reflective cells in corneas of diabetic patients: in vivo evaluation by confocal microscopy. Investigative Ophthalmology \& Visualence. 2005;46(13):879.

14. Tavakoli M, Boulton AJ, Efron N, Malik RA. Increased Langerhan cell density and corneal nerve damage in diabetic patients: role of immune mechanisms in human diabetic neuropathy. Cont Lens Anterior Eye. 2011:34(1):7-11.

15. Ziegler D, Papanas N, Zhivov A, Allgeier S, Winter K, Ziegler I, Brüggemann J, Strom A, Peschel S, Köhler B. Early detection of nerve fiber loss by corneal confocal microscopy and skin biopsy in recently diagnosed type 2 diabetes. Diabetes. 2014;63(7):2454-63.

16. Misra SL, Goh YW, Patel DV, Riley AF, Mcghee CN. Corneal microstructural changes in nerve fiber, endothelial and epithelial density after cataract surgery in patients with diabetes mellitus. Cornea. 2014;34(2):177-81.

17. Messmer EM, Schmid-Tannwald C, Zapp D, Kampik A: In vivo confocal microscopy of corneal small fiber damage in diabetes mellitus. 2010, 248(9): 1307-1312.

18. Tavakoli M, Boulton AJ, Efron N, Malik RA. Increased Langerhan cell density and corneal nerve damage in diabetic patients: role of immune mechanisms in human diabetic neuropathy. Contact Lens \& Anterior Eye the Journal of the British Contact Lens Association. 2011;34(1):7.

19. American Diabetes Association. Standards of medical care in diabetes-2015 abridged for primary care providers. Clin Diabetes 2015;33(2):97-111.

20. Schein OD, Munoz B, Tielsch JM, Bandeen-Roche K, West S. Prevalence of dry eye among the elderly. Am J Ophthalmol. 1997;124(6):723-8.

21. Nichols KK, Foulks GN, Bron AJ, Glasgow BJ, Dogru M, Tsubota K, Lemp MA, Sullivan DA. The international workshop on meibomian gland dysfunction: executive summary. Invest Ophthalmol Vis Sci. 2011:52(4):1922-9.

22. Szalai E, Deak E, Modis LJ, Nemeth G, Berta A, Nagy A, Felszeghy E, Kaposzta R, Malik RA, Csutak A. Early corneal cellular and nerve fiber pathology in young patients with type 1 diabetes mellitus identified using corneal Confocal microscopy. Invest Ophthalmol Vis Sci. 2016;57(3):853-8.

23. Misra SL, Goh YW, Patel DV, Riley AF, McGhee CN. Corneal microstructural changes in nerve fiber, endothelial and epithelial density after cataract surgery in patients with diabetes mellitus. Cornea. 2015;34(2):177-81.

24. Meijering E. Neuron tracing in perspective. Cytometry A. 2010;77(7):693-704

25. Lv H, Liu Z, Li X, Wang W. Effect of lacrimal plugs combined with deproteinized calf blood extract eye gel for filamentary keratitis. J Ocul Biol Dis Infor. 2010;3(4):134-40.

26. He J, Bazan HE. Mapping the nerve architecture of diabetic human corneas. Ophthalmology. 2012;119(5):956-64.

27. Chang PY, Carrel H, Huang JS, Wang IJ, Hou YC, Chen WL, Wang JY, Hu FR. Decreased density of corneal basal epithelium and subbasal corneal nerve bundle changes in patients with diabetic retinopathy. Am J Ophthalmol. 2006;142(3):488-90.

28. Hertz P, Bril V, Orszag A, Ahmed A, Ng E, Nwe P, Ngo M, Perkins BA Reproducibility of in vivo corneal confocal microscopy as a novel screening test for early diabetic sensorimotor polyneuropathy. Diabet Med. 2011;28(10):1253-60.

29. Ziegler D, Papanas N, Zhivov A, Allgeier S, Winter K, Ziegler I, Bruggemann J, Strom A, Peschel S, Kohler B, et al. Early detection of nerve fiber loss by 
corneal confocal microscopy and skin biopsy in recently diagnosed type 2 diabetes. Diabetes. 2014;63(7):2454-63.

30. Zhivov A, Winter K, Hovakimyan M, Peschel S, Harder V, Schober HC, Kundt G, Baltrusch S, Guthoff RF, Stachs O. Imaging and quantification of subbasal nerve plexus in healthy volunteers and diabetic patients with or without retinopathy. PLoS One. 2013;8(1):e52157.

31. Hamrah P, Zhang Q, Liu Y, Dana MR. Novel characterization of MHC class IInegative population of resident corneal Langerhans cell-type dendritic cells. Invest Ophthalmol Vis Sci. 2002;43(3):639-46.

32. Zhivov A, Stave J, Vollmar B, Guthoff R. In vivo confocal microscopic evaluation of langerhans cell density and distribution in the corneal epithelium of healthy volunteers and contact lens wearers. Cornea. 2007;26(1):47-54.

33. Zhivov A, Stave J, Vollmar B, Guthoff R. In vivo confocal microscopic evaluation of Langerhans cell density and distribution in the normal human corneal epithelium. Graefes Arch Clin Exp Ophthalmol. 2005;243(10):1056-61.

34. Mastropasqua L, Nubile M, Lanzini M, Carpineto P, Ciancaglini M, Pannellini T, Di Nicola M, Dua HS. Epithelial dendritic cell distribution in normal and inflamed human cornea: in vivo confocal microscopy study. Am J Ophthalmol. 2006;142(5):736-44.

\section{Submit your next manuscript to BioMed Central} and we will help you at every step:

- We accept pre-submission inquiries

- Our selector tool helps you to find the most relevant journal

- We provide round the clock customer support

- Convenient online submission

- Thorough peer review

- Inclusion in PubMed and all major indexing services

- Maximum visibility for your research

Submit your manuscript at www.biomedcentral.com/submit 